\title{
IN VITRO CYTOTOXIC EVALUATION OF DOXORUBICIN AND CURCUMIN ANALOGUE LOADED MODIFIED CHITOSAN NANOPARTICLES
}

\author{
Anita Sukmawati*, Akhmad Nafarin, RatnaYuliani, Wahyu Utami, \\ Muhammad Da'i, and Nur Aini \\ Faculty of Pharmacy, Universitas Muhammadiyah Surakarta, Surakarta, 57162, Indonesia \\ *E-mail : anita.sukmawati@ums.ac.id
}

\begin{abstract}
Chitosan had been successfully modified by conjugating with folic acid for specific delivery for an anticancer agent. The modified chitosan-folate (chitosan-FA) then prepared into a nanosize particle (NP) and loaded with the active substances, a combination of doxorubicin (DOX) and curcumin analog, 2,5-bis-(4-hydroxy,3,5-dimethyl benzylidene) cyclopentanone (Pentagamavunon-1, PGV-1). In this research, the cytotoxic activity of chitosan-FA NP containing the drugs against MCF-7 breast cancer cell was evaluated. The ionic gelation method was used for preparing of the chitosan-FA NP containing active substances. Physical characterization including particle size and zeta potential of the NP was analyzed using Particle Size Analyzer (PSA), whereas the encapsulation efficiency (EE) was analyzed using ultrafast liquid chromatography (UFLC). Anticancer activity of nanoparticles was carried out using the MTT method. The particle size obtained for chitosan-FA containing active substances was $111.8 \pm 4.11$ $\mathrm{nm}$ with the EE more than $75 \%$ for DOX and around $12 \%$ for PGV-1. The cytotoxic test with MTT assay showed that the DOX and PGV-1 loaded in chitosan-FA NP had anticancer activity against MCF-7 cells with IC 50 value $25.8 \pm 2.55 \mu \mathrm{g} / \mathrm{mL}$ for DOX and $24.7 \pm 0.91 \mu \mathrm{g} / \mathrm{mL}$ for PGV-1 in combination.
\end{abstract}

Keywords: cytotoxic, doxorubicin, modified chitosan, targeted delivery, nanoparticle

(C) RASĀYAN. All rights reserved

\section{INTRODUCTION}

Chitosan, a polysaccharide-based polymer, is the potential polymer for modification as it has active primary amine group. Chitosan also biodegradable, not toxic and has the ability for attaching to the mucosal. ${ }^{1}$ Thus, chitosan can be used as a matrix for drug delivery, particularly for an anticancer agent. One of the alternatives to deliver the active substance to the cancer cell is using nanoparticle (NP). The NP system can protect the active substances by encapsulating them inside the polymer and improving the penetration across the epithelium by endocytosis mechanism. ${ }^{1,2}$ In addition, the encapsulation of active substance inside the nano-polymeric system has benefit for controlling drug release over the extended period. ${ }^{3}$

The chitosan NP containing doxorubicin (DOX) can penetrate inside the melanoma cells by endocytosis mechanism and releasing the drug inside the cell. ${ }^{4}$ Chitosan NP also has anticancer effect by antiangiogenesis and apoptosis as well as the ability to increase caspase enzyme., ${ }^{5,6}$ However, penetration ability and retention of chitosan NP depend on the cell type, location and density of the tumor ${ }^{7}$. Therefore, a specific targeted therapy for delivering of anticancer is needed, particularly when the cancer is spreading to the body. ${ }^{7}$

In order to deliver the drug effectively inside the target cell, the modification is needed by conjugating chitosan with folic acid (FA) ligand. The FA was used as a proposed ligand in this research since it improving particle endocytosis through the folate receptor and transferred into cell organelles and then released the drug into the cell cytoplasm. Yang et al successfully conjugating folate into primary amine of chitosan through amide formation.

The attachment of folate into chitosan polymer can be prolonged the retention of active substance since most of anticancer have a short half-life. Chemical modification on polymer also affected the mechanical

Rasayan J. Chem., 11(4), 1657-1662(2018)

http://dx.doi.org/10.31788/RJC.2018.1144084

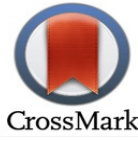


properties of the polymer. Previous research by Yamini and Nanthini (2018) showed that the attachment of succinic and sebacic acid on polyethylene glycol (PEG) 400 influenced the mechanical properties of the modified PEG 400 as well as the cytotoxic activity. ${ }^{9}$ The mechanical properties of chitosan also can be improved by blending chitosan with sodium alginate. ${ }^{10}$

The other alternative for reducing the toxicity of the anticancer agent is using the combination of a drug that can support the cytotoxic effect. By using a combination of drug, the required dose for each drug would be reduced and diminished the side effect of the cytotoxicity agent. According to the previous research, DOX can be combined with a curcumin analog, 2,5-bis-(4-hydroxy,3,5-dimethyl benzylidene) cyclopentanone (pentagamavunon-1, PGV-1) to induce apoptosis in cancer cell. ${ }^{11}$ The combination of active substances was entrapped using a nano-polymeric system of chitosan modified FA (chitosan-FA) NP. By using chitosan-FA NP system, the active substances can be specifically delivered inside the target cell and increasing retention of the particle inside the cell. ${ }^{3,6} \mathrm{We}$ successfully prepared and characterized the DOX and PGV-1 loaded into chitosan-FA NP in our previous research. ${ }^{12}$ Thus, the cytotoxic activity of the chitosan-FA in MCF-7 breast cancer cell line needs to be evaluated. The cytotoxic activity of the NP then evaluated using 3-(4,5-dimethylthiazol-2-yl)-2,5-diphenyltetrazolium bromide (MTT) assay.

\section{Material}

\section{EXPERIMENTAL}

Chitosan with $95 \%$ deacetylation (pharmaceutical grade, $150 \mathrm{kDa}$,) was obtained from CV. ChiMultiguna, Indonesia and conjugated with folic acid (FA) (Sigma-Aldrich) using N-(edimethylaminopropyl)-N-ethyl carbodiimide hydrochloride (EDC HCl) (Sigma Aldrich) as a coupling agent. The active substances, doxorubicin hydrochloride $(\mathrm{DOX}-\mathrm{HCl})$ were purchased from Sigma Aldrich while 2,5-bis-(4-hydroxy, 3,5-dimethyl)-benzylidine-cyclopentanone (pentagamavunon-1, PGV1) were purchased from Pharmacy, Universitas Gadjah Mada, Indonesia. The other materials such as sodium tripolyphosphate (Na TPP), sodium hydroxide $(\mathrm{NaOH})$ and acetic acid for NP preparation and characterization were purchased from Bratachem, Indonesia. All solvent used for UFLC analysis were in HPLC grade. MCF-7 cell line was obtained from Prof. M. Kawaichi, Nara Institute of Science and Technology (NAIST, Japan) and cultured in Dulbecco's Modified Eagle's Medium (DMEM from Merck) with the addition of Fetal Bovine Serum (FBS, 10\%, Sigma) and 1\% Penicillin-Streptomycin. The reagent for the cytotoxic assay are MTT ([3-(4,5-dimethylthiazol-2-yl)-2,5-diphenyltetrazolium bromide]) from Invitrogen) and Sodium Dodecyl Sulphate (SDS, purchased from Merck).

\section{Preparation of Chitosan-FA Nanoparticle}

Synthesis of the chitosan-FA polymer was done using the method as described in Yang, et al (2010). ${ }^{8}$ Attachment of FA was done using $1 \mathrm{~mol}$ ratio to $5 \mathrm{~mol}$ chitosan using $\mathrm{EDC} \mathrm{HCl}$ as a coupling agent. The ionic gelation method was used for preparation chitosan -FA NP loaded with DOX and PGV-1 as described at Zhang et $a 1^{13}$ with slight modification. Chitosan-FA $(100 \mathrm{mg})$ was dissolved in $200 \mathrm{ml}$ of $0.5 \%$ acetic acid solution with addition of tween $80(0.5 \% \mathrm{v} / \mathrm{v})$ to provide $0.05 \% \mathrm{w} / \mathrm{v}$ polymer concentration in solution. The clear solution of chitosan-FA was obtained by stirring the mixture continuously using magnetic stirrer at $1500 \mathrm{rpm}$ for 3 minutes. The $1 \mathrm{ml}$ of each active substances, DOX and PGV-1, then added to the mixture. The final concentration of DOX and PGV-1 are $2 \% \mathrm{w} / \mathrm{w}$ and $10 \%$ $w / w$ drugs to the polymer, respectively. The mixture continued to stir for 3 minutes. The $\mathrm{pH}$ of the mixture then adjusted to 4 using $1 \mathrm{~N}$ sodium hydroxide. For NP formation, a sodium TPP $(0.1 \%, 20 \mathrm{ml})$ was dripped slowly into the mixture under magnetic stirrer. The mixture then stirred continuously for 4 hours for NP formation. The NP was collected by centrifugation at $12,500 \mathrm{rpm}$. The dry particle was formed by drying the precipitated mass using freeze dryer. The NP stored at $4{ }^{\circ} \mathrm{C}$ and protected from the light. The chitosan NP without folic modification loaded with the same active substances also prepared according to with the same method, but without the addition of tween 80 .

\section{Characterization of the Chitosan-FA Nanoparticle.}

The loaded DOX-PGV-1 chitosan NP was characterized for physical properties, drug loading (DL) and encapsulation efficiency (EE). The size of the particle, polydispersity index (PI) and zeta potential were 
analyzed by diffraction method using particle size analyzer (PSA, Horiba SZ100) at room temperature $\left(25^{\circ} \mathrm{C}\right)$. The Chitosan-FA NP $(10 \mathrm{mg})$ was homogeneously dispersed in $10 \mathrm{ml}$ aqua pro injection and directly evaluated for obtaining size, PI and zeta potential using PSA. All measurements were taken triplicate.

The DL and EE of chitosan-FA NP were evaluated using the direct method and applied for $\mathrm{IC}_{50}$ calculation on DOX and PGV-1 in combination. The NP (10 mg) was dissolved in $500 \mu \mathrm{l}$ acetic acid solution $(0.5 \%)$ under ultrasonic bath and diluted using $2 \mathrm{ml}$ of ethanol. The chitosan-FA polymer then precipitated from the mixture by centrifugation at $12,500 \mathrm{rpm}$. The $20 \mu \mathrm{l}$ of clear supernatant then injected to ultra-fast liquid chromatography (UFLC, Shimadzu LC-20AD) and eluted using methanol:water (in 70:30 ratio) on flowrate $0.5 \mathrm{ml} /$ minute using Cosmosil 5C18-MS-II $(15 \mathrm{~cm}, 4.6 \mu \mathrm{m} ; 5$ $\mu \mathrm{m})$ column. The peak of DOX was detected using a UV detector at $\lambda 233 \mathrm{~nm}$ at 3.6 minutes while the peak of PGV-1 was at $\lambda 350 \mathrm{~nm}$ at 5.8 minutes. The concentration of active substances calculated based on their calibration curve that obtained by preparing a series concentration of active substances and analyzed using UFLC method as described above. All measurements were performed triplicate. The DL $(\% \mathrm{w} / \mathrm{w})$ and $\mathrm{EE}(\%)$ is calculated according to equations 1 and 2, respectively.

$$
\begin{aligned}
& \operatorname{DL}(\% \mathrm{w} / \mathrm{w})=\frac{\text { mass of drug in NP }}{\text { mass of NP}} \times 100 \\
& \mathrm{EE}(\%)=\frac{\text { mass of drug in NP }}{\text { mass of the initial drug used }} \times 100
\end{aligned}
$$

\section{Cytotoxic Activity Assay}

The cytotoxic assay for chitosan-FA NP evaluated using MTT assay. A $10 \mathrm{mg}$ of chitosan-FA NPs containing active substances was dispersed with $300 \mu \mathrm{l}$ of acetic acid until providing a clear solution and diluted to $1 \mathrm{ml}$ with a cell culture media A series of NP concentration within the range of $10 \mathrm{mg} / \mathrm{ml}-$ $0.156 \mathrm{mg} / \mathrm{ml}$ was prepared in the supplemented DMEM medium. The amount of DOX and PGV-1 inside the NP was calculated based on the EE value for calculating the $\mathrm{IC}_{50}$.

The MCF-7 cell was grown-up in supplemented DMEM cell medium until reach confluence and then harvested. The cell then counted for the experiment. The cell was seeded in a 96-well plate with a density of $10^{4}$ cells in each well and the NP dispersed in cell culture media was added in each well and incubated for 48 hours. After 48 hours, a $100 \mu$ of medium was discarded and replaced with $0.05 \% \mathrm{w} / \mathrm{v}$ MTT solution and continued to be incubated for 2 hours. The reaction was ended by the addition of $10 \%$ SDS in $\mathrm{HCl}(0.01 \mathrm{~N})$ when the formazan appeared as the violet color under a light microscope. The absorbance of the treated cell with MTT was measured using ELISA reader at $595 \mathrm{~nm}$. Cell viability was evaluated by comparing the absorbance of the treated cell with MTT and control cell with MTT.

\section{RESULTS AND DISCUSSION}

The synthesis of chitosan- decorated with folate (chitosan-FA) polymer was prepared using the method described. The conjugation of chitosan-FA had confirmed using UV absorption spectra as reported in Sukmawati et al. ${ }^{12}$ The chitosan-FA showed the two high-intensity absorbances ( $\lambda 216 \mathrm{~nm}$ and $282 \mathrm{~nm}$ ) compared to the chitosan polymer without modification. The absorbance peaks related to the shifting of $n$ to $\pi^{*}$ and $\pi$ to $\pi^{*}$ due to conjugation reaction between chitosan and folic acid as well as $\mathrm{C}=\mathrm{C}$ bond transition. The dialysis method for chitosan-FA purification had successfully removed unbound folic acid (FA) and EDC as a coupling agent.

\section{Characterization of Chitosan-FA Nanoparticle}

Chitosan-FA nanoparticle was formed by interaction between positive charge of the amino group in chitosan and cross-linker agent, sodium TPP, which has a negative charge. ${ }^{14}$ The result showed that the chitosan-FA revealed a smaller size of particle compared to the nanoparticle prepared from chitosan as described in our previous research ${ }^{15}$ (Table-1) due to the addition of tween 80 during chitosan-FA NP preparation. The addition of folic group into chitosan polymer affected the molecular size of the polymer. The higher molecular size of chitosan-FA compared to the chitosan tend to produce the bigger size of the 
particle as evaluated in the previous experiment. ${ }^{16,17}$ Therefore, tween 80 applied in NP preparation in order to produce nano-range particle by the act as a stabilizer during nanoparticle formation and inhibit crystal growth. ${ }^{18}$ However, the size of the NP was influenced by the amount of tween 80 added during NP preparation. ${ }^{12,19}$

Table-1: The Physical Characterization of Chitosan and Chitosan-FA Nanoparticle containing DOX-PGV-1 (n=3)

\begin{tabular}{c|c|c|c}
\hline Polymer & $\begin{array}{c}\text { Particle size } \\
(\mathrm{nm}) \pm \mathrm{SD}\end{array}$ & $\begin{array}{c}\text { Polydispersity index } \\
(\mathrm{PI}) \pm \mathrm{SD}\end{array}$ & $\begin{array}{c}\text { Zeta potential } \\
(\mathrm{mV}) \pm \mathrm{SD}\end{array}$ \\
\hline Chitosan $^{*}$ & $812.8 \pm 11.94$ & $0.50 \pm 0.21$ & $(+) 24.5 \pm 0.90$ \\
\hline Chitosan-FA & $111.8 \pm 4.11^{* *}$ & $0.20 \pm 0.08$ & $(+) 11.2 \pm 0.40$
\end{tabular}

* A. Sukmawati, et al, Adv. Sci. Lett., vol. 23, no. 12, pp. 12486-12488, (2017)

** A. Sukmawati, et al, IOP Conf. Ser. Mater. Sci. Eng., vol. 311, p. 12024, (2018)

The chitosan-FA NP had positive charge related to the amine group in chitosan (Table). The positive charge of the NP would give the great influence for interacting with the cell as the cell surface has a negative charge. However, the chitosan-FA NP showed the lower zeta potential compared to chitosan NP indicated that the chitosan NP tend to be aggregated. NP would be in the high stability in the zeta potential more than $\pm 25 \mathrm{mV}$. It revealed that the presence of a folic molecule in the chitosan backbone affected the stability of the NP. ${ }^{20}$

The drug loading (DL) and efficiency encapsulation of the active substances was determined using the direct method. Amount of PGV-1 added during NP preparation is 5 times higher than DOX according to the molar ratio as suggested in the previous experiment. ${ }^{11}$ The result showed that the DL of DOX was higher compared to the PGV-1 (Table-2) although the DOX added during NP preparation is lower than PGV-1. It revealed that the DOX had better interaction with chitosan-FA rather than PGV-1. Charge repulsion between chitosan and PGV-1 might affect the interaction between chitosan and PGV-1 since both chitosan and PGV-1 had a positive charge. However, although DOX had a positive charge, it showed better interaction with chitosan as revealed by the high EE (more than 70\%). In this experiment, the DOX was used in hydrochloride salt, therefore it might influence the solubility of active substances during NP preparation. Comparing the EE of PGV-1 in chitosan-FA NP with chitosan NP, there is no significant increase of $\mathrm{EE}(\mathrm{p}>0.05)$ by conjugating folic molecule into chitosan molecule indicating that presence of the folic group in chitosan could not improve drug-polymer interaction.

Table-2: Drug Loading (\%w/w) and Encapsulation Efficiency (\%) of DOX and PGV-1 in Chitosan and Chitosan-FA Nanoparticle $(\mathrm{n}=3)$

\begin{tabular}{c|c|c|c|c}
\hline Polymer & \multicolumn{2}{|c|}{ Drug Loading $(\% \mathrm{w} / \mathrm{w})$} & \multicolumn{2}{c}{ Encapsulation Efficiency (\%) } \\
\hline & DOX & PGV-1 & DOX & PGV-1 \\
\hline Chitosan $^{*}$ & $1.6 \pm 0.02$ & $1.1 \pm 0.03$ & $78.4 \pm 1.15$ & $11.7 \pm 0.27$ \\
\hline Chitosan-FA & $1.6 \pm 0.13$ & $1.2 \pm 0.04$ & $78.7 \pm 6.61$ & $12.1 \pm 0.39$ \\
\hline
\end{tabular}

* A. Sukmawati, et al, Adv. Sci. Lett., vol. 23, no. 12, pp. 12486-12488, (2017)

\section{Cytotoxic Activity of Chitosan-FA Nanoparticle}

Evaluation of the cytotoxic activity of chitosan-FA NP containingDOX-PGV-1 was carried out using the MTT assay. A single solution of DOX and PGV-1 were used in this experiment as a positive control. The death cell appeared as a plump under a light microscope after treated with chitosan-FA NP. The metabolic activity of cell after NP treatment can be measured by adding the MTT reagent into the cell to form formazan. The absorbance of formazan in each well then measured using ELISA reader. The control cell showed the higher formazan formation compared with the treated cell related to the high metabolic activity within the control cell. It indicated that the NP treatment on the MCF-7 cell induced the death. The $\mathrm{IC}_{50}$ was calculated based on the $\log$ concentration versus cell viability. According to the concentration of chitosan-FA NP, the $\mathrm{IC}_{50}$ in chitosan-FA NP was reached more than $1000 \mu \mathrm{g} / \mathrm{ml}$ due to the lower entrapment of active substances in chitosan FA NP (Table-3). Based on the EE calculation, it can be concluded that the $\mathrm{IC}_{50}$ equivalent with $25.8 \mu \mathrm{g} / \mathrm{ml}$ of DOX and $24.7 \mu \mathrm{g} / \mathrm{ml}$ of PGV-1. This value is higher compared to the positive control of DOX and PGV-1 in the single solution form. DOX and PGV-1 as a positive control had available in a form of a solution in the cell medium during 48-hours of treatment. In this case, all drugs would interact with the cell and rapidly affected the cell. 
Table-3: The $\mathrm{IC}_{50}$ of DOX and PGV-1 in MCF-7 cell after 48-Hour Treatment.

\begin{tabular}{c|c|c|c}
\hline & \multicolumn{3}{|c}{$\mathrm{IC}_{50}(\mu \mathrm{g} / \mathrm{ml})$} \\
\hline & $\mathrm{NP}$ & Equivalent of DOX & Equivalent of PGV-1 \\
\hline Chitosan-FA NP & $1853.2 \pm 174.2$ & $25.8 \pm 2.55$ & $24.7 \pm 0.91$ \\
\hline Positive control & & $14.1 \pm 1.88$ & $22.9 \pm 1.97$ \\
\hline
\end{tabular}

The different phenomenon was found in the delivery of drugs using chitosan-FA NP. The higher $\mathrm{IC}_{50}$ value of DOX in chitosan-FA NP might relate to drug retaining inside the matrix due to the ability of chitosan-FA to interact with the active substance. However, the $\mathrm{IC}_{50}$ value of PGV-1 is similar either in a single solution or in chitosan-FA NP. This occurrence suggested that the interaction of chitosan-FA matrix with PGV-1 is lower compared with a chitosan-FA matrix with DOX. The poor interaction between chitosan-FA with PGV-1 also implicated in low EE of PGV-1 inside chitosan-FA NP. The IC $\mathrm{I}_{50}$ is time-dependent manner as shown in previous research by Fang et al (2012). This research suggested that the release of DOX from iron nanoparticle was time-dependent therefore affected the $\mathrm{IC}_{50}$ of DOX. ${ }^{21}$ The similar phenomena could occur in this experiment, hence further investigation on the time-dependent cytotoxic evaluation and drug release profile need to be convinced.

\section{CONCLUSION}

The loaded DOX-PGV-1 chitosan-FA NP implicated the cytotoxic effect on MCF-7 cell line. However, the $\mathrm{IC}_{50}$ of the active substances is higher compared to the single solution of DOX and PGV-1 as it might relate to the slower release of the drug from the chitosan-FA matrix. The slow release of drugs from chitosan-FA NP can be useful for maintaining drug concentration inside the cell for a longer period.

\section{ACKNOWLEDGMENT}

The authors would like to thanks Ministry of Research, Technology and Higher Education of Indonesia (RISTEKDIKTI) as a source of funding for this research through research grant scheme. In addition, we appreciate our home institution, Universitas Muhammadiyah Surakarta, Indonesia for a kind of support in facilities and Faculty of Pharmacy, Universitas Gadjah Mada, Indonesia for supplying PGV-1 for this research.

\section{REFERENCES}

1. A. Rampino, M. Borgogna, P. Blasi, B. Bellich and A. Cesàro, Int. J. Pharm. 455(1), 219 (2013), DOI: $10.1016 /$ j.ijpharm.2013.07.034.

2. S.Bisht and A. Maitra, Cancer 1(4), 415 (2009), DOI: 10.1002/wnan.043.

3. M. Conti et al. In Vivo 20(6A), 697 (2006).

4. K.A. Janes, K., M.P. Fresneau, A. Marazuela, A.Fabra and M.J. Alonso, J. Control. Release 73(2), 255 (2001), DOI: 10.1016/S0168-3659(01)00294-2.

5. Y.S. Wimardhani et al. J. Oral Sci. 56(2), 119 (2014), DOI: 10.2334/josnusd.56.119.

6. Y. Xu, Z. Wen and Z. Xu, Anticancer Res. 30, 5103 (2010).

7. V.M. Gaspar et al., Pharm. Res. 32(2), 562 (2014), DOI: 10.1007/s11095-014-1486-0.

8. S.Yang et al. Bioconjugate Chem. 21, 679 (2010), DOI:10.1021/bc9004798.

9. B.Yamini and R. Nanthini, Rasayan J. Chem. 11(2), 440 (2018), DOI: 10.31788/RJC.2018.1121992.

10. S.E. Cahyaningrum, N.Herdyastuti, A. Firdausa and D. Yanrita, Rasayan J. Chem. 10(3), 959 (2017), DOI: 10.7324/RJC.2017.1031635.

11. A.Hermawan et al., Pharmacon 12(2), 55 (2011).

12. A. Sukmawati, W. Utami, R. Yuliani, M. Da'i and A. Nafarin, IOP Conf. Ser. Mater. Sci. Eng. 311(1), 012024 (2018), DOI: 10.1088/1757-899X/311/1/012024.

13. H. Zhang, M. Oh, C.Allen and E. Kumacheva, Biomacromol., 5, 2461 (2004), DOI: 10.1021/bm0496211.

14. I.O. Wulandari, D.J.D.H. Santjojo and R.A. Shobirin, Rasayan J. Chem., 10(4), 1348 (2017), DOI: 10.7324/RJC.2017.1041907. 
RASĀYAN $J$. Chem.

Vol. 11 | No. 4 |1657 - 1662| October - December | 2018

15. A. Sukmawati, M. Da'i, R. Yuliani, S. Anggraeni and D. Wahyuningsih, Adv. Sci. Lett, 23(12), 12486 (2017), DOI: 10.1166/asl.2017.10798.

16. L.A. Caetano, A.J. Almeida and L.M.D. Gonçalves, Mar. Drugs., 14(5), 1 (2016), DOI: 10.3390/md14050090.

17. A. Sarwar, H. Katas and N.M. Zin, J. Nanoparticle Res. 16(7), 2517 (2014), DOI: 10.1007/s11051014-2517-9.

18. S. Rajaram and R. Natham, Res. J. Pharm. Biol. Chem. Sci. 4(4), 820 (2013).

19. R. Asasutjarit, C. Sorrachaitawatwong, N. Tipchuwong and S. Pouthai, Int. J. Medical, Heal. Biomed. Bioeng. Pharm. Eng., 7(9), 309-311 (2013).

20. R.K. Salar and N. Kumar, Resour. Technol. 2(4), 199 (2016), DOI: 10.1016/j.reffit.2016.10.006.

21. C. Fang et al., J. Control. Release 162(1), 233 (2012), DOI: 10.1016/J.JCONREL.2012.06.028.

[RJC-4084/2018] 